\title{
Palaeopoetics: Prefatory Notes Toward a Cognitive History of Poetry
}

\begin{abstract}
As a verbal artifact, a poem draws upon a number of nonverbal structures in the brain. Even before the emergence of language, certain behaviors had to have been in place, e.g. an increased capacity to bind perceptual data and process them as single events (episodes) and the ability to reproduce perceived actions (mimesis). These two evolutionary phases, according to Merlin Donald, preceded language, but to allow for the emergence of that specific activity we know as poetry, two other behaviors must also have evolved - play and tool-making. Play supplied episodes with frames and as-if intentionality, while tool-making skills enhanced mimesis by crafting artifacts that were saved and reused. Palaeopoetics, which I would define as the study of cognitive skills preadaptive to verbal poiesis, is a project that examines play, episodic awareness, mimesis, and tool-making as forming the common foundation upon which all the myriad varieties of oral and written poetry have been built.
\end{abstract}

How did poetry begin? From a cognitive-evolutionary point of view this is not an unanswerable question. If we agree that poetry is a complex operation that the brain performs, agree that the complexity of the brain consists of the structures and functions, albeit modified, of its own evolutionary past, then we should agree that poetry, too, should be able to reveal something of its own beginnings in its structures and functions. But then, of course, the follow-up question becomes "what is poetry?". A convenient first answer would be: "Poetry" is what most people around the world and down through the ages have assumed it to be, namely, the practice of making self-contained, formally patterned verbal compositions. In the course of this essay I will propose some 
approaches that might eventually lead us to sharpen these fuzzy specifications, but I am willing to begin with them.

To ask how poetry began is not a trivial question, either. A search for poetry's "deep history" (Small 2007) will take us into certain ancient places that still form the subsoil and bedrock of our inner landscape. Poetry, no less than psychology, has a long past but only a short history. That long past still haunts this art form, which perhaps explains why many have revered it as an uncanny, even sacred, instrument of knowledge. This power, I will suggest, derives from the fact that poetry relies on and reactivates the deepest layers of our cognitive architecture and, in so doing, shows us the way down those neural pathways of our own long past.

The theoretical map I will take on this venture into palaeopoetics is that provided by Merlin Donald in his books The Origins of the Modern Mind (1991) and $A$ Mind So Rare (2001). I will first outline his chronology, then insert into it two evolutionary factors, play and tool-use, that seem to me to require closer examination as traits preadaptive to the emergence of poetry.

\section{A. Donald's Four Stages of Consciousness}

First, a few clarifications. By "consciousness" Donald means a state (not a thing): a nonsleeping state of awareness. Most mammals have gradations of consciousness - "active, vigilant, and wide-awake states and those that are passive, unfocused, and marked by a reduced level of activity" (Donald 2001: 118). How humans came to possess the neural architecture that characterizes their specific alertness is the story he has endeavored to tell over the past decade and half. In his writings, he has outlined four evolutionary stages, each representing the individual's closer and more productive engagement with the social environment. Over the past two million years it was culture, that is, "collective mentality" that drove cognitive evolution. "Cultures are more efficient than individuals at exploiting the fitness value of genetic variations, which might otherwise have a negligible impact" (Donald 2001: 259). ${ }^{1}$

We must also be very clear about what Donald means when he uses the word "stage". It is a period marked by the onset of a newly emerging trait, a successful adaptation that builds upon previously expressed traits and confers

1 "This", he adds, "is the basis of Baldwin's effect". This effect, named for the philosopher and evolutionist, James Mark Baldwin (1861-1934), is an adjustment of behavior that allows some individuals and communities to survive in the face of novel circumstances. It is a deliberate adaptation that preserves genetic variations in a given population. 
reproductive advantages on its possessors, advantages that promote population growth, which in turn helps spread this trait. We must keep in mind that this process in which an advantageous rewiring of the neural network selects some hominids to be our ancestors and others to go extinct can take millions of years to complete. (His first two stages did take that long; his third took perhaps one hundred thousand years and, his last, a mere five thousand).

We must understand, moreover, that a "stage" is not a "phase", in the sense of a temporary condition. Biological evolution, even the culture-driven evolution that Donald narrates, does not feature stages that a species "passes through", as we commonly say of children who are exhibiting predictable agedetermined behavior. An evolutionary stage, and the neural structures that characterize it, may be superseded by another stage but is never eliminated. Instead, it serves as a platform upon which the next structures are built. While much of each older stage is still in use, much of it remains in reserve, available, if needed, to be retrofitted for later uses. As Donald tells us, these stages are "successive layers in the evolution of human cognition and culture. Each stage continues to occupy its cultural niche today, so that fully modern societies have all four stages simultaneously present' (Donald 2001: 260; italics added).

His four stages are, in brief:

1) The Episodic, associated with the perception and storage of whole events. This evolved with the primate apes.

2) The Mimetic, associated with the communication of thoughts through actions, for example, gestural representation and the teaching of skills through showing. This began among early hominids and became fully developed in Homo erectus.

3) The Mythic, associated with linguistic communication - telling, as distinct from showing; symbolic signs, as distinct from indices and icons. This appeared at the beginning of our own subspecies, Homo sapiens sapiens, at some point between 100 thousand and 50 thousand years ago.

4) The Theoretic, associated with the transcription and external storage of symbolic signs, viz., writing. Begun some 5 thousand years ago, this led to the development of literate cultures and what we customarily refer to as "civilizations". 
Now, for a little more detail. In the episodic stage, first fully realized in primates, the brain achieved the capacity to integrate hundreds of separate percepts, "batched together in coherent chunks" (Donald 2001: 201). An animal able to take in and organize a wide array of information into a single "event-perception" of that size no longer relies solely on instinct and conditioned reflexes, but can now assess and adapt itself to novel situations. The social skill that episodic cognition drove, and also benefited from, was mindreading, the ability to interpret the intentions of conspecifics. Determining the truthfulness or deceptiveness of others' responses to one's emotive and gestural signs, comparing the details of this ongoing episode with similar episodes stored in long-term memory, and then modifying one's own responses accordingly - all these processes took increased time and brain capacity.

In modern humans, such episodes can extend in duration well beyond the interval we identify with "working memory" - 7 items, plus or minus two, within a period of 20 seconds (Miller 1956). As a unit of conscious, voluntary action, a cognitive episode, according to Donald, is usually much longer than the span of online short-term ("working") memory, though shorter than intervals storable in long-term memory. Donald therefore suggests we regard the episode as a period of active cognition, an event contained within an "intermediate time frame", the duration of which in modern humans can sometimes extend beyond an hour. As an example, he cites an animated conversation among several persons. "Such events are stored as single, unified episodes, and future behavior is affected by memories of such episodes. This memory for specific, coherent, detailed events is the essence of episodic cognition" (Donald 2001: 47, 195-201; Ericson \& Kintsch 1995).

Donald's second stage, the mimetic, represents the further socialization of our early ancestors by supplementing mind-readable involuntary indices with deliberately communicative gesture. "Mimesis is an analog style of communication that employs the whole body as an expressive device. Mimesis is really about acting. It manifests itself in pantomime, imitation, gesturing, sharing attention, ritualized behaviors, and many games. It is also the basis of skilled rehearsal, in which a previous act is mimed, over and over, to improve it" (Donald 2001: 240). In so doing, it served "as a mode of cultural expression and solidified a group mentality, creating a cultural style that we can still recognized as typically human" (Donald 2001: 261). A mimetic performance, such as a ritual or an athletic event, can further enlarge an "intermediate term time frame" to an interval of many hours. 
Mimesis is also the basis of teaching and learning. Techniques of hunting, food gathering and preparation, fire making, and shelter construction - all these had to have been transmitted through visual observation and hands-on motor replication. The young mimed their elders, the less skilled mimed their more skilled neighbors. A mimetic performance could be stored in episodic memory and a mimetic skill could be stored in procedural, or motor, memory. The sensory and motor intelligence of prelinguistic humans had now prepared them for their next evolutionary stage, one in which that intelligence could be communicated through a non-analog channel - speech.

The analog mind, which up till then had been the sole cognitive operating system, receives impressions and rearranges its neural networks accordingly. These networks "form impressions in essentially the same way a time-exposed astronomical photograph does, by passively gathering data over time. Several exposures to an object allow neural networks to extract consistencies in the world that relate to the object (...) In effect, the neural net classifies the world, without preconceptions about what the major classes ought to be. In contrast, symbolic computation takes in the world in prepackaged categories. It is given the major classes of experience in advance" (Donald 2001: 155). With language emerged what Donald calls the "hybrid mind", which is partly analog and partly symbolic. $^{2}$

With language, the bonding and shared attention that mimetic culture had enhanced was accompanied by the enlarged capacity of the human brain to input and manage even larger and more complex episodic events. Further social complexity co-evolved with neural enlargement, since self and other, even when they share attention, can have different motives for doing so, different feelings, and differently remembered experience to compare with their current objects of attention. Mind-reading requires that each person consider these differences even in the process of cooperation and do so through multilevel parallel processing. Language not only communicates thoughts - it also layers, embeds, and imbricates them, so that now, "under the right circumstances, we can maintain several parallel lines of thought, each in a different mode (...) Running frames within frames concurrently is routine for our species (...) Our

2 As for its genetic origin, Donald argues against the modular theories associated with Chomsky and Fodor. Calling his view "biocultural", he places the "origin of language in cognitive communities, in the interconnected and distributed activity of many brains (...)", p. 252. 
human cognitive style is linked to this multifocal consciousness, and language, in particular, is highly dependent on this feature" (Donald 2001: 258-59).

What Merlin Donald describes here is dialogic give-and-take, the sort of improvised oral discourse that challenges our episodic-cognitive skills. But by naming this the mythic stage, he chooses to characterize the preliterate speech stage as that of narrative compositions, rather than of free-form conversations. He does so perhaps to highlight the oral/literate divide by suggesting how this narrative format, with its memorial storage, imposes limits on information and consequently on human consciousness. But the distinction between 1) an improvised oral discourse and 2) a traditional oral composition, i.e., myth, is extremely important to the evolution of poetry and is one that I will return to shortly.

Finally, when he comes in his story to the invention of writing, he is positioned to confirm his central premise: that which has made us different from all other species has all along been our ability to draw upon information external to the individual brain. The evolutionary stages that demonstrated how consciousness could be shared (the episodic stage), reenacted (the mimetic stage), coded and communicated orally (the mythic stage), and then inscribed and made available to others (the theoretic stage) are milestones that mark a steady trajectory from egoistic isolation to social integration. Reading this "deep history", we, the sharers of the final stage, can recognize our ancestors as the men and women who opted for mutual trust, in the face of considerable risks deception, information management, and thought control. We, the beneficiaries of this two-million-year-long leap of faith, we with our bookshelves and our high-speed connections to the Internet, are the children of risk-taking parents. Moreover, as Donald reminds us, we so deeply embody in our brains that ancestral heritage that our present now contains their past.

\section{B. Episode and Mimesis within Social Play Frames}

One kind of episode that even our pre-hominid ancestors understood well was social play. Our mammalian forebears must have had a mutual awareness that some threatening displays might not be what they seem, enough skill in mindreading to interpret outwardly aggressive behavior, under certain circumstances, as non-aggressive in intent. We assume so because they and we still exhibit this awareness. "How do animals read play intention in any conspecific? Cooperative social play may involve rapid exchange of information on intentions, 
desires, and beliefs" (Bekoff \& Byers 1998: xvi). Gregory Bateson had his own term for this pre-play exchange: he called it a "metacommunication" (Bateson 1972, Collins 1991: xxiii-xxiv). This was a signal that invited the addressee to enter into what Bateson called a "play frame" within which actions, for example, chasing, nipping, and sparring, would not indicate the sort of hostility that might otherwise lead to injury or death.

Through its power to redefine behavioral indices, social play introduced into mammalian cognition a triple-framed episode, a social encounter (1) within which an event (2) is negated and transformed into another event (3). In semiotic terms, the real encounter uses a metacommunication as an index to negate the indices of aggression (in event 2) and simultaneously transform them into mere icons of aggression (in event 3). This negation-cum-transformation is essential to episodic social play, because it keeps the meanings of these two simultaneously performed events, each with its own sign function, separate and distinct. ${ }^{3}$

The evolutionary advantages of this semiotic play include the opportunity to practice fight-and-flight motor programs in the safety of a band or sibling group and, since play signifies alliance, the reinforcement of social solidarity. But the pertinence of mammalian social play to cultural evolution lay in its preadaptive uses. First, it prepared our hominid ancestors to perceive a social encounter as a distinct episode, framed within a familiar context. Then, as human communities grew in size, this social script could be extended from individuals in one-on-one play to whole groups in coordinated play. By this time, humans had entered what Donald calls the mimetic stage.

The mimetic stage introduced imitation, a specific subset of mimesis (Donald 2005: 286). As imitation, mimetic play is not merely repeated, coordinated action or the repeated demonstration of a skill and its rehearsal or the conveying of information through iconic gesturing - it is deliberate roleplaying, the representation, on the part of one or more persons, of one or more other persons, animals, or objects. This is also quite different from episodic play, which involves two socially identified individuals engaged in enacting a socially recognized play script - two dogs, for example, barking and taking turns

3 It is important to distinguish frame-doubling, such as I will be discussing in this essay, from frame-shifting. The latter, as Seana Coulson demonstrated in Semantic Leaps, is essential to comedic play of the sight-gag and the joke variety. It starts by leading us to believe that one particular interpretive frame governs a given episode, then suddenly pulls that out from under us, revealing the real frame. Any future cognitive history of poetic genres would find differences in framing extremely significant. 
chasing one another, or two humans exchanging soft punches to one another's shoulder to communicate good-natured bonhomie. In short, while episodic play is initiated by a person the apparent meaning of whose actions is contradicted by his metacommunicated intentions, mimetic play is initiated by a person who imitates someone or something other than himself.

Mimetic play differs from episodic play in yet another respect: it allows for multiple participants (actors) and the presence of a spectator-audience. The latter element helps establish a sense of social solidarity by arousing and synchronizing the emotional responses of the community by imitating an episode, or a series of episodes, that has inherent relevance to it. During such a high-arousal episode, typically an action with life-and-death implications, not only is the time duration extended into the "intermediate term", but the moment-to-moment input flow is expanded. Recent research into what has been called the mirror neuron system offers further confirmation of Donald's mimetic theory when it argues that the human brain is capable of converting visually perceived motions of conspecifics into motor neuron firings that mirror those movements. ${ }^{4}$ Accordingly, the movements of the performers evoke incipient motor responses in the brain and central nervous systems of their viewers, which may prompt them to empathize with, and thereby more accurately interpret (mind-read) the dramatis personae.

Mimetic play also enlarges the frame available to episodic awareness. Within this frame, it easily embeds multiple one-on-one episodic frames, both of play and of non-play, within its imitative performances. For example, characters in a drama may playfully or deceptively imitate others or act in deadly earnest. Here, the episodic and the mimetic play frames prove asymmetrical, for an instance of one-on-one episodic play does not normally embed mimetic play. If, for example, I give my companion a friendly shove, I am not imitating someone else doing this. It is my act. I intend it. This fact lends further support to the theory that, in the evolution of human play behavior, mimesis followed and built upon episodic awareness.

These differences notwithstanding, mimetic play shares with episodic play a three-part structure: a social event that frames two other events, each of these

4 For discussions of the mirror neuron system and its implications, see Stamenov and Gallese, eds., Mirror Neurons and the Evolution of Brain and Language, esp. the articles by Fogassi and Gallese, Rizzolatti et al., Voegeley and Newen, Li and Hombert, Studdert-Kennedy, Stamenov, Bichakjian, and Morrison. Another valuable collection is that edited by Hurley and Chater, Perspectives on Imitation, vol.1, esp. the separate articles by Gallese and Hurley. 
governed by its own sign function. The play frame that circumscribes a mimetic performance, for example, a ritual or heroic pageant, would first need to be produced before it could metacommunicate the index that this is a performance, not a "real" action and before performers could present actions (movements, gestures, vocalizations, and so forth) as iconic of some other actions and conditions. Imagine, for example, the following mimetic scenario. A person appears before the assembled clan. He is a well-known elder with a particular personality and life history, but now he is imitating a mighty hunter tracking a bear. That he is imitating is the index; what he is imitating in his facial expressions, his proud gestures, his tensely alert gait, is the icon of a person that all know he could never have been, even in his youth. Coming together with family and neighbors to view this performance is itself an episode, a real event. This factually real episode (1) frames a factually unreal episode, the mimetic performance (2), and this indexically marked unreal episode frames an iconically marked virtual episode (3). This triplicity defines fictionality. ${ }^{5}$

Before I conclude this brief discussion of the palaeopoetics of play, I will comment on how two features of mimetic performance may have intensified the experience of memory and anticipated some of the structures and themes we have come to associate with poetry. I will begin with working memory.

We naturally associate accelerated heart beat and breathing with a higharousal episode and with the increase in quantity of information and speed of processing. A performance of rapidly repeated movements and sounds can therefore induce in viewers a heightened state of consciousness. Ululation, drum beats, whirling, stamping - all these stylized replications use as their formula repetition=intensity and serve to represent the expanded input of the working memory confronting an arousing, perhaps overwhelming perceptionevent. When forms imitate themselves, their repetitive structure constitutes what Roman Jakobson (1958) called "iterative form" and saw operating in verbal compositions on the levels of semantics, syntax, and phonological expression. Even earlier, Suzanne Langer (1953) declared rhythmic patterning to be the form of feeling and, as such, an aesthetic universal across all the arts.

While agreeing with them that iterative form is a root mode of aesthetic experience, I think that William Butler Yeats made a more interesting point when he wrote:

5 I have borrowed the bear-hunt scenario from Donald (Donald \& Andreassen 2007: 76). The semiotic analysis is my own. 
The purpose of rhythm, it has always seemed to me, is to prolong the moment of contemplation, the moment when we are both asleep and awake, which is the one moment of creation, by hushing us with an alluring monotony, while it holds us waking by variety, to keep us in that state of perhaps real trance, in which the mind liberated from the pressure of the will is unfolded in symbols. If certain sensitive persons listen persistently to the ticking of a watch, or gaze persistently on the monotonous flashing of a light, they fall into the hypnotic trance; and [auditory] rhythm is but the ticking of a watch made softer, that one must need listen, and various, that one may not be swept beyond memory or grow weary of listening; while the patterns of the [visual] artist are but the monotonous flash woven to take the eyes in a subtler enchantment (Yeats 1959: 159).

To apply this theory of rhythm, we need first to transpose it from its specific context, i.e., how poetic texts are written and subsequently read. We need to consider how his explanation of the "purpose of rhythm" might apply to a mimetic performance even before the emergence of language and do so with the understanding that this function underlies all future instances of rhythmic patterning.

Having made our mental adjustments, we will now need to situate iterative form on a continuum, at a point somewhere between sleep and waking consciousness, between monotony and variety, where occurs the "moment of contemplation", "the moment of creation". This intermediate state, he says, is equivalent to a hypnotic trance, which, from the Latin transitus, is transitional between two states. This in turn brings to mind the liminal state created for initiands by performers of a rite of passage.

This "purpose of rhythm" is not simply to excite participants and onlookers by inducing a state of hyper-alertness - it has also a calming function, a monotonous regularity that helps them modulate their response to mimetic play and thereby contemplate it as both unreal and real - as marked by the indexical sign of fiction and the iconic sign of truth. Rhythm, Yeats suggests, permits the mind to lay aside its egocentric will and become "unfolded in symbols", that is, to unfurl all the mental images that are stored within it and that the words evoke. By "symbols", he does not, of course, mean symbolic signs, the words, those arbitrary signifiers that, with indices and icons, comprise the Peircean sign-types. Yeats's symbols are word-cued mental icons that, in a prelinguistic mimetic spectacle, would be visual percepts. 
Repetition, by the speed of its pulses, thus serves to represent the sort of intense experience of episodic awareness that can extend working memory into an "intermediate term" of lengthened duration and, by its regularity, prepare participants to contemplate images. These images, which in a prelinguistic performance would be visually displayed in the spectacle, would be meaningful to the onlookers only as iconic representations of a collective episodic memory. Events that the individual brain does not store unless they were sufficiently arousing, it retrieves from a long-term system that Donald's fellow Canadian cognitivist, Endel Tulving, appropriately named "episodic memory" (For his acknowledgement of Tulving, see Donald 2001: 201.) During a mimetic performance, episodes that portray ancestors or heroes are received and cognitively processed by the same mechanisms each viewer uses to retrieve his or her own past events. Both actor and viewer understand that these are not their own stored memories, yet they are like these. Their experience of the narrative sequence of past events becomes situated once again in the liminal, intermediate space between the unreal and the real - the virtual, or fictive, zone. The mimetic performance, with or without spoken components, thus builds upon and exploits two modes of episodic awareness: one is an intense and complex experience of the ongoing present, the other is a recollection of the experiential past.

The iterative aspects of these two - on the one hand, a rapid rhythmic repetition of movements and sounds and, on the other hand, a slower, visual representation of past events - correspond rather closely to Nietzsche's wellknown distinction in The Birth of Tragedy between the Dionysian and Apollinian factors at the heart of Greek tragedy and modern music drama. These two gods represent for him the polar oppositions of self and selflessness, reason and rapture, dream and dance, vision and music. At the Apollinian pole, we enjoy an illusory, yet stabilizing, belief in the unique wholeness of our self, a belief grounded in the principium individuationis (the principle of individuation). The latter, as he understood from Schopenhauer, was formed by our sense of existing in time and space - in particular moments and particular places. At the Dionysian pole, this sense of separate individuality surrenders to a mystical participation in a larger reality.

Why Nietzsche's polarity has seemed so intuitively compelling is not because of what it says about Greek culture or the birth of tragedy, so much as what is says about the way we frame our experiences and situate ourselves within those frames. We experience Apollinian cognition as the retrieval of 
episodic memories, predominantly visual images of scenes from our autobiographical past. It is precisely these that underlie one's principium individuationis and provide assurance that, every morning one wakes up, one does so as the identical self that last night went to sleep and that, over a lifetime of many decades, one is that same person who once was a child - in short, that one continues to be one.

If our re-cognition of the past gives us our self-consciousness, our cognition of the present gives us our other-consciousness. In our dealings with things and persons, we seem to ex-sist, to stand outside ourselves, in a fluid, ongoing, constantly updated mix of multisensory information. This, for Nietzsche, is the Dionysian pole, a spatiotemporal field suffused with music, dancing, masking, and metamorphosis. Within it we are unself-conscious because the self, as a framing concept, no longer governs our experience. Standing outside our self, we intuit our own and everyone's existence as a collective ecstasy.

Here Donald's first two hominizing stages, the episodic and the mimetic, come together as complementary opposites. The Apollinian pole is the new, individuated self, created by episodic memory, the system that stores retrievable, autobiographical events specifiable in terms of time and space (This is one characteristic that Tulving uses to distinguish episodic from semantic memory, which is our store of general knowledge and beliefs.) The Dionysian pole, on the other hand, is the immediate experience of event-perceptions, i.e., our episodic awareness in an extended present, one that in a mimetic culture is also enlarged by communal activities, for example, hunting, foraging, tool-making, food-sharing, and child-rearing, episodes in which the perceiving self is submerged in the flow of social action and in the ritual representations of these actions. When the Apollinian and the Dionysian appear together in the mimetic performance, each draws power from the other. ${ }^{6}$

As soon as language became a medium for mimetic play, it could incorporate these two iterative modes even in the absence of dancers, drummers, actors, and spectacle. The solo voice of the storyteller, singer, or rhapsode could produce iterative form through prosodic patterning and iterative content by naming and impersonating gods and heroes of the past. These vocal patterns

6 The broad aesthetic implications of this cognitive polarity of past and present, memory and perception, might lead historians of the arts to consider 1) the relation between visual art (painting and sculpture that imitate memory images) and music (auditory experiences of acoustical events in the here-and-now) and 2) the relation, within the verbal art genres, between epic (a recollected and retransmitted narrative of a common cultural past) and drama (an imitation of actions, with or without music, dance, and pageantry, in an ongoing present). 
created the ground within which the virtual persons introduced in the narrative could become visualizable figures for the audience. Phonological patterns stir motoric responses in an audience, while words stir sensory, predominantly visual, images. This doubleness, which Nietzsche called the union of the Dionysian with the Apollinian, was possible because prosody and semantics are noninterferent functions of the brain. We can do them both at the same time because our motor and sensory (here, visual) systems, while linked, are separately wired, a coordination essential to another behavior preadaptive to poetry, namely, tool-use.

\section{Objects and Instruments}

Most evolutionists agree that tool-making and language are the two traits that have most distinguished and distanced us from all our fellow animals and that tool-making preceded true language by at least two million years. But when the discussion turns to if and how these skills may have at some point co-evolved, agreement is hard to come by. Were humans, whose hands were occupied with the use and manufacture of things, now obliged to "gesture" with vocal sounds? Was the capacity to remember and employ sequences in making things used subsequently to string sounds together in some meaningful syntax? And how did social organization affect the development of both skills? My own observations, which follow, are based on the assumption that the visuomotor and proprioceptive experiences that our Upper Paleolithic ancestors had when using simple manual tools were virtually the same ones we have today when using comparable tools. A phenomenological approach to tool-use, supported by cognitive psychology, ought therefore to help us form valid inferences that can, perhaps, shed light on the preadaptive origins of language and those linguistic constructions we call poems.

The use of found objects is probably as old as the earliest great apes (20 million years ago), but the earliest modified, i.e. hand-crafted, tools date only from about 2.5 million years ago. Discovered in the Olduvai Gorge of northern Tanzania, these mark the beginning of the Lower Paleolithic era, which 
extended from 2.5 million to 300 thousand years ago, the period that Donald characterizes as the mimetic stage. ${ }^{7}$

It is safe to assume that hominids used found objects, such as boughs and stones, as tools for millions of years before their descendants learned to fashion these into scrapers, hafts, axe heads, and other artifacts. With all our technical sophistication, we modern humans still employ improvised tools. Walking in hilly terrain, we might find a straight stick on the ground and use it as a staff or drink brook water from a burdock leaf curled into a cup or hammer open a handful of hickory nuts between two stones. Human survival skills, including the ability to perceive the distinguishing details of edible, medicinal, and poisonous plants, to fish, to trap and hunt animals, to fashion temporary shelters and garments - these skills and the tools we forage to practice them with are no mean achievements and continue as parts of our hominid repertoire.

Such ad hoc instruments as a stick, a leaf, or a pair of stones, once used, we would toss by the wayside, but, if we carried with us a knife or a fish hook and line, we would keep them, because reusable tools such as these cannot be readily found where and when we need them.

Tool-making, perhaps the crowning achievement of the mimetic stage, demonstrated the advantages of slow, patient, repetitive actions. The careful flint-knapping that produced the tapered spearhead, the scraping that produced the long shaft, and the months of instruction and rehearsal of the throw and the thrust - all these mimetic behaviors paid off in the successful hunt and the sharing of meat with family and clan. With artifacts such as these, humans were no longer dependent on what they found lying about, the "naturefacts" that could serve as improvised tools. They now had portable equipment that could be reused and, when necessary, repaired or improved. Products of a mimetic culture based on the value of repetition, these were made for repeated use. This portable tool kit prepared their owners to venture into unfamiliar territory, protected them if they encountered hostile others, and, as valuable property, could be used as gifts or traded for other commodities.

There is also something magically metamorphic about these items. In Being and Time (1926/1962), Martin Heidegger noted how from our human perspective a thing can shift its status suddenly from that of an object to that of an

7 To be precise, Donald estimates that the mimetic peaked in " $H$. erectus $2 \mathrm{M}-0.4$ Mya" and was followed thereafter by the mythic stage of "H. sapiens sapiens 0.5 Mya-present" (Donald 2001: 260). 
instrument. Our awareness of being situated "out there", somewhere, anywhere, in the world, categorizes all things either as "present-to-hand" (vorhanden), i.e. simply there as objects, or as "ready-to-hand" (zuhanden), in which case they are considered pieces of equipment, i.e. tools. If, for example, my path in the woods leads me to a boggy spot and I see a half-rotted log nearby, I might decide to lay it down across that spot and use it as a kind of pontoon bridge. When I do so, I convert that object into an instrument, something vorhanden into something zuhanden. Then, having crossed, should I glance back at that log from further up the path, I find that it is no longer a bridge-like instrument, but has turned itself back into an object. Of course, it could have already turned itself back into that object, if, as I stepped onto it, it had broken apart (Heidegger 1962: 92-93, 96-107). A similar shift could befall a manufactured tool. Consider a hammer lodged neatly in a toolbox beside a set of screwdrivers and pliers of different designs and graduated sizes. Nestled there, it is an object among other objects, a testimony perhaps to the owner's technical finesse, perhaps also to his obsessive orderliness. But if I need it and he lends it to me, the hammer begins to change. I first heft it, sense its balance and comfortable grip, and then I swing it to nail a piece of clapboard to a wall stud. Doing so, I feel how "ready-to-hand" it is - in fact, sense it as an actual extension of my hand. Alternatively, if, after a few blows, its head flies loose, this instrumental extension of my hand becomes an object once again. As Heidegger remarks (whose hammer example is always ready-to-hand, by the way), this piece of equipment becomes at this point "conspicuous". This conspicuousness [Auffälligkeit] presents the ready-to-hand as in a certain unreadiness-to-hand" (Heidegger 1962: 102-103).

Michael Polanyi pondered further on what it meant for such a tool to be an extension of its user:

When we use a hammer to drive in a nail, we attend to both nail and hammer, but in a different way. We watch the effect of our strokes on the nail and try to wield the hammer so as to hit the nail most effectively. When we bring down the hammer we do not feel that its handle has struck our palm but that its head has struck the nail. Yet in a sense we are certainly alert to the feelings in our palm and the fingers that hold the hammer. They guide us in handling it effectively, and the degree of attention that we give to the nail is given to the same extent but in a different way to these feelings. The difference may be stated by saying that the latter are not, like the nail, objects of our attention, but instruments of it [my italics]. 
They are not watched in themselves; we watch something else while keeping intensely aware of them. I have a subsidiary awareness of the feeling in the palm of my hand which is merged into my focal awareness of my driving in the nail.

He then mused:

(...) Think how a blind man feels his way by the use of a stick, which involves transposing the shocks transmitted to his hand and the muscles holding the stick into an awareness of the things touched at the point of the stick (Polanyi 1958: 55-56).

Over a decade earlier, Maurice Merleau-Ponty had indeed thought of how a blind man feels his way and concluded:

The blind man's stick has ceased to be an object for him, and is no longer perceived for itself; its point has become an area of sensitivity, extending the scope and active radius of touch (...) In the exploration of things, the length of the stick does not enter expressly as a middle term. There is no question here of any quick estimate or any comparison between the objective length of the stick and the objective distance of the goal to be reached. To get used to a hat, a car or a stick is to be transplanted into them, or conversely to incorporate them into the bulk of our own body. Habit expresses our power of dilating our being in the world, or changing our existence by appropriating fresh instruments (Merleau-Ponty 1945/1962: 143).

When we incorporate them, tools give us the power to extend ourselves outward into the world and, as we extend, they magically vanish into our foreground. Yet, as Polanyi pointed out, this vanishing is not absolute: the tool continues to be held in subsidiary awareness, that particular level of alertness we must continue "intensely" to maintain.

This phenomenon to which all three philosophers refer is figure-ground perception, a doubleness fundamental to all sensory modalities and to human consciousness generally. The object, when it becomes zuhanden, becomes an instrument and as such enters the ground of its user, while its point of contact with the world becomes that user's vorhanden object. To use the hammer-nail dyad, the hammer, joined to the hand-arm-shoulder of the worker, vanishes into that worker's ground, while the nail becomes the focalized figure. 
While the issues of whether or how tool-use may have facilitated the emergence of cultural representations and symbolic signs systems, such as language, continue to be hotly debated, I think we can all agree to consider the implications of some basic parallels. The distinction between found tools that are used and discarded and made tools that are used, saved, and reused broadly corresponds to the distinction that exists between improvised actions, skillful procedures such as foraging, hunting, and tool-making, on the one hand, and mimetic artifacts, imitations of these actions in the form of a painting, a sculpture, a ritual, a dance, or a drama, on the other hand. When we apply this tool-modeled distinction to linguistic expression, we note that speech is always available to be improvised and then discarded, whereas verbal artifacts, both oral and written, are made, used, and reused. Be it a song, a chant, a charm, a gnomic rhyme, a proverb, a joke, or a narrative, a verbal artifact is a made thing, a poiêma, that we preserve, carry about with us, and reuse. These word-shaped poiemata differ from other verbal phenomena not only because they exhibit iterative form and iterative content, but because they share with prized, finecrafted tools this one essential aspect: iterative performance.

Moreover, as vorhanden artifacts, these instruments are means by which their users continually extend themselves outward into space - in this case into mental space. What that language-generated space is and what beings inhabit it becomes the final topic of this palaeopoetic speculation.

\section{Symbols and the Invention of the Future}

Before the Paleolithic Era, human time had featured an expanded perceptual present, in which episodes happened, and a retrospected past, in which the more important episodes in one's life were stored for later consideration. But the future was still, and had already been for millions of years, a zone of worries, evoked sometimes by a rustle of leaves or a cracking of twigs, a whiff of smoke or a scent of tiger. But with tools, this very shallow breathing space could be pushed back and made more manageable. Using objects to extend and amplify their bodily powers, Homo habilis and Homo erectus could better protect themselves from predators, hunt larger prey, and do so in ways that gave them increasing confidence when in unfamiliar environments. With improved security, our ancestors could also afford to plan further ahead, for, just as toolmaking had taught them how certain sequences of action could produce successful outcomes, tool-use also allowed them to coordinate projects requiring sequenced activities and do so with less fear of untoward interrup- 
tions. Among those projects was travel, notably the migration of tool-using Homines erecti from Africa eastward to China and Indonesia, the first great human migration of 1.7 million years ago (The second great migration was that of Homo sapiens sapiens, our direct ancestors, who, beginning in Africa about 50 thousand years ago, succeeded, over the next 40 thousand, in traversing and sparsely settling the entire habitable globe.)

Tool manufacture having evolved from the simple Oldowan hand axes (beginning 2.6 million years ago) to the Acheulean spear heads (1.7 million-200, 000 years ago), high-protein meat became more available and human aggregations grew in size. With population growth, skill-based divisions of labor must have been introduced and, to the extent that every individual needed to share in the work of the community in order to share in its benefits, the principle of reciprocal altruism became the governing ethos. This was the Paleolithic golden rule: I will do unto others a kindness (whatever the immediate cost to myself) with the understanding that, if ever I need the same, those others will do that unto me (whatever the immediate cost to them). Persons unwilling to abide by this rule would be banished from the group; those found to be slackers or cheaters would be punished.

Individuals needed to observe others' behavior and, according to Terrence Deacon (1997: 398), gauge their "future probability of altruism on the basis of past experiences". This was a particularly crucial element in sexual selection: the hunter who shared his kill with his mate was permitted sexual access. "The pairbonding relationship in the human lineage is essentially a promise, or rather a set of promises that must be made public. These not only determine what behaviors are probable in the future, but, more important, they implicitly determine which future behaviors are allowed and not allowed; that is, which are defined as cheating and may result in retaliation" (Deacon 1997: 399). If language was a necessary medium for promises, it had to have co-evolved with tool-use, because it was their mastery of tools that provided humans something finally worth promising to one another. Moreover, if, over several million years, most humans ever born were offspring of promise-bonded parents, the traits associated with reciprocal altruism would likely survive and influence the emergence of related traits.

As Deacon sees it, the most important spin-off of sex-for-food bonding was the symbolic sign. "Symbolic culture was a response to a reproductive problem that only symbols could solve: the imperative of representing a social contract" (Deacon 1997: 401). Since a contract obliges the parties who enter into it to 
perform stipulated actions, some of them of a very general sort, representing these obligations using an old-style semiotics would pose considerable problems.

Deacon's insight was that nonhuman primates are under no pressure to evolve symbolic communication because they never have to confront the problem of social contracts. As long as communication concerns only current, perceptible reality, a signaller can always display or draw attention to some feature as an index or likeness of the intended referent. But once evolving humans had begun to establish contracts, reliance on indices and resemblances no longer sufficed. Where in the physical world is a 'promise'? What does such a thing look like? Where is the evidence that it exists at all? Since it exists only for those who believe in it, there is no alternative but to settle on a conventionally agreed symbol (Knight et al. 2000: 9-10).

A social contract, then, is an abstraction projected as a speech act into a conceptual invention, the human future. It is a conventionally agreed upon arrangement that can only be represented by a conventionally agreed upon sign. Words, as vehicles of the contract, can represent that contract because each one of these is itself a contract. I can "give my word" to you because it is not only my word, but our word, a symbol the significance of which you and I both agree on, an a priori agreement upon which every subsequent agreement is ultimately premised. Consequently, this "symbolic species" of ours, after millions of years trying to mind-read one another's intentions, has now, in relatively recent millennia, left its hominid cousins behind in the bush and gone off to settle an unseen savannah of discourse that can never fully exist, a future that only promises to be real.

Most current paleoanthropologists agree with Deacon and Donald that, of course, symbolizing preceded words, that visual symbols in the form of body paint and other decorations seem to have long preceded the more systematic symbolizations of 50-30 thousand years ago. The recent discovery of pigment ochre in a South African coastal settlement, estimated as 164 thousand years old, supports the assumption that humans of the mimetic stage shared their social beliefs through visible symbols and ritual performances (Marean et al. 2007). As an ongoing human behavior, ritual, together with tool-making, appears to be the principal link between mimetic and mythic cultures. 
First of all, ritual, as a behavioral artifact, requires a mimetic play frame within which indexical and iconic signs and materials, such as fire, water, stone, bread, wine, and earth, become charged with whatever meanings the cultural tradition has assigned them. In the mind of believers, such objects and the officiants that use them may even become transformed into other things and persons. In short, a ritual is a complex symbolic sign that represents a complex set of human intentions and obligations. Once the mythic stage began, these meanings could also be conveyed through spoken narratives that were either acted out in the ritual or inserted to interpret the symbolic acts and objects of the ritual. Thus, the indexical and iconic signs that rituals had woven into complex symbols were now accompanied by the pure semiotic stuff of symbolization, namely language. Ritual became, as the Cambridge Anthropologists used to say, a combination of "things done" (drômena) and "things said" (legomena) (Harrison 1912/1962: 327-31).

Though it may allow for spontaneous actions within it, there is little improvisation in a ritual. Composed out of mimetic drômena, a ritual is no less an artifact than is a manufactured tool. Just as a tool that is made, preserved, and reused, can shift from the status of an object to that of an instrument, so too can a ritual. As an object, it can be referred to, scheduled, rehearsed, its location cleaned and decorated. As an instrument, though, it exists only in the episodic present of its performance and only in the minds of its participants as they extend through it into the meanings it represents.

Similarly, the verbal element within it, its legomena, is speech, but not conversational speech. Unlike conversation, ritual speech is neither freely generated, turn-taking, unpredictable, nor creative. Verbal artifacts, including proverbs, charms, and other "simple forms" (Jolles 1930, Welsh 1978), exist external to the individual and prior to their utterance. Though stored in individual brains, their content and their expression are wholly determined by the community that regulates them through collective and professional memory. ${ }^{8}$

As a system of meanings, ritual tends to be closed to outsiders, who need, at the very least, to be first instructed in the relation between the symbols and their signifieds. But at times and places where a number of ritualized traditions

8 I am not suggesting here that rituals and other oral artifacts are mnemonically stored as efficiently as are written texts. Textual criticism is a discipline that oral societies could not practice, because after a generation or two no one could prove that a given text had ever been corrupted. Tradition does change oral texts, but the one thing it does not change is the belief that such texts do not change. 
interpenetrate, when urban and rural, commercial and agricultural, foreign and native populations must mix and work together in a given society, secular performances and narratives appear in, for example, in 5th- and 4th-century Athens, in early Imperial Rome, and in 16th-century Europe. Designed to be meaningful across different belief systems, cosmopolitan verbal artifacts borrow aspects of ritual and use them to examine the specific consequences of belief. The makers of these artifacts feel free to mine the conceptual substructure of language, metaphor, and employ this instrument to generate new concepts and whole new virtual worlds for Homo symbolicus to explore. No longer limited to episodic and mimetic play, he now has verbal play to exercise his nimbleness. And as for the perennial theme of this serious play, it is Homo symbolicus himself, that animal who yearns for the future that his unique semiotic system has embedded in his mind. ${ }^{9}$

However this protagonist is presented, he or she mirrors ourselves as we intently intend our own future, anxiously hoping that the trust we invest in others will be reciprocated and that our own untrustworthiness will never be detected. For us, the reusers of a verbal artifact, there is a curious doubleness: we identify with this persona, who at every moment stands on the brink of an unenterable future, while, like gods, we also know in advance how he or she will conclude. We remember this persona's future, because it is now absolutely past, vollkommen vergangen, as Goethe and Schiller said of epic. As we re-witness or reread these iterated actions, we experience the rhythmically pulsing episodic present as a time that, for the fictive persona, is moving in the direction of an unpredictable future, yet we also understand that this action has been drawn from our collective episodic memory and, as such, represents an immutable past. In not knowing the future, this persona is as vulnerable as we are, so we feel fear; because this persona's future-oriented strivings, unlike our own, now belong to the past, we feel pity. When we hear Oedipus pronounce his oath against the man who is concealing from him the identity of his father's killer, we know so much more than he does:

9 Religious thinkers have also, of course, meditated long and hard on this human predicament. Some have sought to reify that future to which all human commitments point as an ultimate place where kept promises in life would, after death, be reciprocated and breaches of the social contract punished. If such a place existed, it would, in effect, confirm the validity of language and the moral paradigm that is its most important construction. As far as our species is concerned, in the beginning was indeed the word. 
I solemnly forbid the people of this country,

Where power and throne are mine, ever to receive that man

Or speak to him, no matter who he is, or let him

Join in sacrifice, lustration, or in prayer.

I decree that he be driven from every house (Sophocles 1939: 12).

\section{E. Conclusion}

I began this venture in palaeopoetics by asking what cognitive mechanisms had to have been in place before the behavior that we call poetry could emerge. Then, after outlining Merlin Donald's four-stage model of cognitive evolution, it seemed to me that to answer my question I would need to consider two specific behaviors: social play, which preceded his first two stages (the episodic and the mimetic), and tool-use, which preceded his last two (the mythic and the theoretic).

Social play, that instinctive mammalian behavior, profoundly influenced the episodic and mimetic stages. As episodic play, it helped establish the frame as a way to sharpen event- perception and did so by developing a triply-framed script: 1) an encounter marked by a metacommunication according to which a given set of aggressive indices 2) would be negated and transformed into 3) a set of aggressive icons. Mimetic play adopted this triad and then applied three types of repetition to it: iterative form, which simulated episodic perception in the present, iterative content, which simulated episodic memory retrieval from the past, and, modeled after the reuse of tools, iterative performance. This latter type of repetition, also used in rituals, influenced the themes explored in the third form of play, verbal play, by presenting characters that strive to control their futures, while, from the observers' perspective, belonging to a completed past.

Tool-use was preadaptive, not simply analogous, to our production and use of mimetic artifacts, such as rituals, and finally of verbal artifacts, such as poems. The way we dilate (Merleau-Ponty) into the physical instruments we use, while maintaining them in subsidiary awareness and simultaneously objectifying their points of contact through focal awareness (Polanyi), is exactly how we hear or read verbal compositions. Our subsidiary processing of the textual instrument, whether oral or literate, eludes our conscious attention, but, as a ground defines a figure, subsidiary awareness makes it possible for us to direct our conscious attention to the separate referents in the text, especially the agents of events. 
These latter objects of our attention, the personae of the text, act only in the present but do so in relation to two absent realms, a past where promises were made and expectations formed and a future where these will or will not be fulfilled. In doing so, these agonists exhibit the predicament of a species that, some 50 thousand years ago, turned its back on the world that other animals inhabit and wandered off into a strange, time-haunted universe of discourse. This is a world with a brief present continuously being swallowed by an insatiable past and forever at the edge of an ungovernable future, a time-realm that is the special gift of language. In creating this future, it filled it with promises and their correlatives, trust and hope, but then added other less comforting gifts - resentments, anxieties, and longings - and gave us the words to rehearse them over and over in our minds. Yet, hiding at the bottom of this Pandora's box and last to flutter forth, lay that other gift of language, poetry, the instrument of verbal play we use to mitigate these ills and make, as Robert Frost once said, our momentary stay against confusion.

\section{References}

Bateson, G. (1972). A Theory of play and fantasy. In his Steps to an ecology of mind. New York: Chandler.

Bekoff, M. \& Byers, J. A. (1998). Animal play: Evolutionary, comparative, and ecological perspectives. Cambridge: Cambridge University Press.

Collins, C. (1991). Poetics of the mind's eye: Literature and the psychology of imagination. Philadelphia: University of Pennsylvania Press.

Coulson, S. (2001). Semantic leaps: Frame-shifting and conceptual blending in meaning construction. Cambridge: Cambridge University Press.

Deacon, T. W. (1997). The Symbolic species: The Co-evolution of language and the brain. New York: Norton.

Donald, M. (2005). Imitation and mimesis. In S. L. Hurley \& N. Chater (Eds.), Perspectives on imitation from neuroscience to social science. Volume 2, Imitation, human development, and culture (pp. 283-300). Cambridge, Mass: MIT Press

Donald, M. (1991). Origins of the modern mind - three stages in the evolution of culture and cognition. Cambridge, MA: Harvard University Press.

Donald, M. (2001). A mind so rare - the evolution of human consciousness. New York: Norton.

Donald, M. \& Andreassen, L. (2007). Consciousness and governance: From embodiment to enculturation - and interview. Cognitive Semiotics 0 (Spring 2007), 68-83.

Hurford, J. R., Studdert-Kennedy, M., \& Knight, C. (1998). Approaches to the evolution of language - social and cognitive bases. Cambridge, UK: Cambridge University Press.

Harrison, J. E. (1962). Themis: A Study of the social origins of Greek religion. New York: Meridien. Original publication 1912.

Hurley, S. L., \& Chater, N. (2005a). Perspectives on imitation from neuroscience to social science Volume 1, Mechanisms of imitation and imitation in animals. Cambridge, Mass: MIT Press. 
Hurley, S. L., \& Chater, N. (2005b). Perspectives on imitation from neuroscience to social science. Volume 2, Imitation, buman development, and culture. Cambridge, Mass: MIT Press.

Jolles, A. (1930). Einfache formen, legende, sage, mythe, rätsel, spruch, kasus, memorabile, märchen, witz: Halle (Saale): M. Niemeyer.

Knight, C., Studdert-Kennedy, M., \& Hurford, J. R., (Eds.) (2000). The Evolutionary emergence of language - social function and the origins of linguistic form. Cambridge: Cambridge University Press.

Knight, C., Studdert-Kennedy, M., \& Hurford, J. R. (2000). Language: A Darwinian adaptation? In Knight, C. et al. (pp.1-15).

Langer, S. (1953). Feeling and form. New York: Scribners.

Marean, C. W., Bar-Matthews, M., Bernatchez, J, Fisher, E., Goldberg, P., Herries, A., et al. (2007). Early human use of marine resources and pigment in South Africa during the Middle Pleistocene. Nature 449, 905-908.

Merleau-Ponty, M. (1962). The Phenomenology of perception. (Trans. C. Smith). London: Routledge \& Kegan Paul. Original work published in 1945.

Nietzsche, F. W., Geuss, R., \& Speirs, R. (1999). The Birth of tragedy and other writings. Cambridge texts in the history of philosophy. Cambridge, U.K.: Cambridge University Press.

Polanyi, M. (1958). Personal knowledge: Toward a post-critical philosophy. Chicago: University of Chicago Press.

Sophocles. (1939). The Oedipus cycle: An English version. Trans. D. Fitts and R. Fitzgerald. New York: Harcourt Brace, and Jovanovich.

Stamenov, M., \& Gallese, V. (Eds.) (2002). Mirror neurons and the evolution of brain and language (Advances in consciousness research 42). Amsterdam: John Benjamins.

Tulving, E. (1983). Elements of episodic memory. Oxford psychology series, no. 2. Oxford [Oxfordshire]: Clarendon Press.

Welsh, A. (1978). Roots of lyric primitive poetry and modern poetics. Princeton, NJ: Princeton University Press.

Yeats, W. B. (1974). Essays and introductions. London: Macmillan. 